\title{
Editorial
}

\section{Product development partnerships (PDPs) for neglected diseases: considerations on governance}

\author{
CORINNA SORENSON* \\ LSE Health, The London School of Economics and Political Science, UK
}

Neglected diseases (NDs), such as malaria, tuberculosis, cholera, schistosomiasis, and Chagas disease, result in an estimated 35,000 deaths per day worldwide (DNDi, 2006). They are also associated with a considerable disease and social burden caused by chronic disabilities, disfigurement, reduced productivity, and stigma (WHO, 2007). Indeed, NDs pose a major challenge to the fulfilment of the Millennium Development Goals (MDGs), notably in Sub-Saharan Africa, Asia, and the Americas.

Despite their social and economic impact, minimal investment has been made to research and develop (R\&D) treatments (e.g., vaccines) for NDs, principally because they are not considered a lucrative commercial 'market' (Trouiller et al., 2002; Mrazek and Mossialos, 2003). The absence of R\&D means that there are no or few treatments available for NDs, accounting for less than $2 \%$ of new drugs marketed during the last 25 years, and many of the limited available treatments are outdated, ineffective, and unsafe (Trouiller et al., 2002; Yamey, 2002). While various 'push' and 'pull' mechanisms (e.g., tax credits, advanced purchase commitments) have been put forth to spur the development of new technologies and better align the social and financial incentives required to meet this aim, they have been somewhat ineffective, underused, or not sufficiently pursued (Brogan and Mossialos, 2006; Fehr et al., 2006).

One such mechanism, Product Development Partnerships (PDPs), has received considerable traction and support over the last ten years. The rise of PDPs was largely predicated on the recognition that the public (government, non-governmental organizations) and private sectors (philanthropic foundations, pharmaceutical companies) are solely unable to garner the resources, technical capacity, and political will required to make significant advances towards improved access to ND treatments. This particular partnership model provided a viable solution to the risk and uncertainty inherent to the drug development process. A recent article by Buckup (2008) argues that PDPs are warranted in

*Correspondence to: Corinna Sorenson, LSE Health, London School of Economics and Political Science, Houghton Street, London WC2A 2AE, UK. Email: C.Sorenson@lse.ac.uk 
situations where the process of producing certain outcomes (i.e., new ND drugs) is complex, where incomplete or imperfect information exists, and when said outcomes are uncertain. This is indeed true of most NDs, as their R\&D pathway is long and unpredictable, with most investors and funding bodies realizing that there is no guaranteed return on investment. This is one reason why investment in PDPs is significantly skewed towards private philanthropic foundations (e.g., Bill and Melinda Gates Foundation) (Moran et al., 2005), a partner that is often willing and able to carry a significant amount of risk and one that possesses the necessary technical expertise to alleviate a certain degree of uncertainty. Private sector participation in PDPs also stemmed from a growing emphasis on 'corporate social responsibility' and 'venture philanthropy', which created momentum for private actors to engage in practices traditionally considered the domain of the public sector, such as service delivery and the formation of partnerships. Thus, PDPs essentially answered the call for a more joined-up, collective approach between public and private actors in both developed and developing countries to govern product development and, more broadly, for providing global public goods for communicable disease control (Reich, 2000; WHO, 2007). About $75 \%$ of ND drug projects are led by various PDPs, such as the Medicines for Malaria Venture (MMV), covering about 80\% of NDs (Moran et al., 2005).

Despite the growth in PDPs and the resources invested in their establishment, there has been minimal investigation of the actual governance of these partnerships. Rather, most of the existing literature and discourse has principally focused on two areas: (1) why and under what circumstances PDPs have been or should be established and (2) whether or not these partnerships are effective, in specific terms of bolstering the ND drug pipeline. The objective of this editorial is to address this gap by providing some initial conceptualizations on their governance, and concludes by maintaining that a theoretical and empirical approach is needed that views the PDP structure, actors, and broader contextual factors in interaction, in order to fully elucidate their governance.

The premise and arrangement of PDPs fit within the existing literature on a 'network society' (Castells, 2000), where multi-stakeholder action toward shared objectives has emerged as a new paradigm for social and institutional organization. PDPs, as a form of networked governance, serve to reconfigure structural linkages and roles between public and private actors, eroding traditional sectoral barriers to collaboration and participation. A key tenet of networks is that they create more inclusive, flexible, and open processes for participation amongst partnership members and other stakeholders, whereby negotiation and persuasion serve as the main tools of governing (Benner et al., 2005; Risse, 2007). This, in turn, helps to build trust and cooperation and bridge divergent interests within a given PDP, and facilitates adequate legitimacy and accountability both internal and external to the partnership (Reinicke and Deng, 2000; Witte et al., 2000). Such processes also aid to establish political and social capital in the wider (global) public sphere by furthering 
transnational and trans-sectoral participation in ND drug development (Sorenson and Torfing, 2003; Benner et al., 2005; Dryzek and Niemeyer, 2006).

Given their networked arrangement, how does governance proceed within PDPs and what elements or factors influence this process? Drawing upon insights from a wide body of literature, including neo-institutionalism, governmentality, and constructivism, one can begin to explicate how governance transpires in PDPs and what factors internal and external to the partnership shape this process.

Consistent with institutionalist premises (Scharpf, 1997; Kooiman, 2003), the actor-structural arrangement of PDPs can be seen as defining the roles that actors play within networks as well as prescribing the issues discussed (e.g., which NDs or treatments are pursued) and how they are dealt with (Marsh and Smith, 2000). This process is influenced by the different 'logics', power resources and interests, and symbolic or normative constructions held and promulgated by the various actors in the partnership. Over time, particularly in PDPs that are more formalized, these rules, norms, and practices of governance become institutionalized to guide actor behaviour within the network and effectuate the broader global health landscape (Marsh and Smith, 2000).

Institutional logics within PDPs can be understood as 'sets' of material practices and symbolic constructions that constitute actor behaviour and, ultimately, partnership governance (Friedland and Alford, 1991). While it is generally assumed that all actors in partnerships share common goals and interests, sufficient attention must be given to the fact that such governance arrangements create environments where competing logics collide, as different sectors relate to distinct areas of institutional life and interests. For example, in terms of the mode of governance for the PDP, the public sector logic would base governance practices on inputs, procedural rules, bureaucracy, and controls. Conversely, the private sector logic would support governance according to outputs and performance management. Such differences in logic would also be apparent with regards to the identity of the partnership, its source(s) of legitimacy, authority structure, and investment approach.

The role of logics in PDP governance is further complicated by the fact that such partnerships often bring together actors from Northern and Southern countries, who arguably share divergent practices and norms. For instance, while improved access to new ND drugs is surely an objective shared by both Northern and Southern partners, views and values around how this objective should be reached, for example, may differ greatly between these actors. Some (Halabi, 2004) have argued that the potential of global [health] governance structures to close traditional operational and participatory governance gaps, depends on whether the norms and principles underlying their practices benefit and are shared and supported by Southern partners and constituencies. While this conjecture holds significant merit, differences in the logics used in 
governing PDPs are not a problem per se, as conflicts are an inevitable feature of partnerships; they are only an issue if they are not dealt with effectively. What is important is that there is a process whereby all stakeholder problem assessments, approaches, and interests are heard and considered, even if divergent, via transparent debate and mediation (Benner et al., 2005). The ability to meet this aim, however, would certainly be influenced by perceptions of legitimacy and accountability of individual partners and the overall governance structure, fairness of process, and diffusion of power.

To that end, the relative power position of each partner and the power dynamics between them act as a mediating influence on PDP governance. As argued by Barnett and Duvall (2005) and others (Brand, 2000; Buse and Harmer, 2004), studies of global governance forms have been inattentive to the totality of power. This is somewhat surprising given that the inclusion of a plurality of actors in partnerships undoubtedly reshapes power relations, and that distributed governance forms, such as PDPs, are considered (in principal) a model of more complex and presumably sophisticated power-sharing. It is important that the normative problem-solving bias frequently attached to public-private partnerships does not obstruct a realistic view on power relations when assessing these governance forms.

The governmentality literature provides some insights and perhaps theoretical grounding into analyzing power in more detail and the mechanisms and reasoning involved in the governance processes of PDPs. As viewed through the governmentality lens, there are multiple forms of power in any governance arrangement, ranging from repressive to constitutive (Rose, 1999; Foucault, 2000; Bang, 2004). While these concepts have been traditionally applied to government functions, it is feasible that PDPs, as well as other networked global governance structures, are forming and employing new 'governmentalities' for co-governance in global health. Such governmentalities encompass the principal loci of power and the technologies and rationalities employed in governing.

As maintained by Fraser (2003) and Bull et al. (2004), the locus of power in globalized governance structures has shifted from the public realm toward being increasingly privatized. In the context of many global health partnerships, this has entailed erosion in the authority and responsibilities of traditional international health organizations, such as the World Health Organization (WHO), and an expansion of power to private bodies and, to some degree, civil society (Deacon et al., 2003; Kohlmorgen, 2006). Consequently, the logics of private members assert a certain level of influence over the governance of the PDP, with regards to setting ND policies and research agendas, or establishing the norms and procedures of governance. This is especially true where resource-transfer defines much of the partnership, as is characteristic of most PDPs. Critics assert that this new governmentality of 'privatization' serves to enhance the power of the private sector at the expense of other critical voices and downgrades the role and political capital 
of governments, intergovernmental agencies, and civil society in governance (Martens, 2003, 2007). This claim may hold some weight given the lack of representation of NGOs and affected communities on partnership governing boards (Buse and Harmer, 2007) and, what some may consider, a privileged position assumed by the private sector, especially foundations, in decisionmaking processes.

Amongst complex governance arrangements, however, one might question a 'zero-sum conception of power', where an increase in the power and influence of private actors equates to a simultaneous reduction in public power and authority. Sending and Neumann (2006) provide an alternative view that such changes are an expression of a different rationality or logic, where private actors (and other non-state actors, such as civil society) are redefined from a passive object of governance to be acted upon by the state into entities that are both an object and subject of governance. In this sense, by providing the seed finance and periodic capital contributions to support the establishment and maturation of the PDP, private actors, such as the Bates and Rockefeller foundations, have conferred a certain level of legitimacy and procedural authority on both themselves as partners and the overall partnership. This, in turn, has resulted in a high degree of agency for the private partners to formally and informally set the direction on the partnership and for the partnership to shape the broader field of ND governance. Such actions allow public actors, namely governments, to meet their own objectives for improved access to ND drugs.

As intimated above, an important consideration in examining the power dynamics of PDPs for ND is the role of developing countries in these partnerships. This is particularly important, as the structural arrangement of PDPs has the potential to offer Southern governments and organizations the opportunity to influence global health strategies and policies. Moreover, the prevailing discourse in this regard highlights the fact that such partnerships must look to their long-term sustainability and an ultimate redistribution of power and resources toward affected communities. Despite the inclusive conceptions of public-private partnerships, and networked governance more generally, in practice there has been minimal developing country engagement and involvement in PDPs. Although many clinical trials for new ND drugs take place locally, their respective decision makers are not often involved in substantiating research plans and in other realms of governance, and may not even be active partners (Buse, 2004; Tucker and Makgoba, 2008). While the various reasons for the lack of representation of these key constituencies have been posited elsewhere (Widdus, 2003; Buse, 2004; Buse and Harmer, 2007), a meaningful Southern role and influence is likely to be only realized in certain policy issues and in particular partnership arrangements, where powerful actors do not pursue, at least in the long-term, their own self-interests and allow for consideration of actors and institutions that do not adhere to their logics and interests (Kohlmorgen, 2006). This is a real risk in networked governance forms, given 
their self-organization and hybrid nature, where divisions of power, accountability, and transparency are often unclear.

Certainly, such concerns between Northern and Southern actors also apply to the public-private actor nexus, where there are broader questions whether membership in such partnerships is simply a conduit for various actors to justify and maximize their own self-interested goals and mobilize action in support of these aims. For example, pharmaceutical companies may support and justify certain research agendas or policies put forth by the PDP in attempts to maximize profits or expand markets for ND. This would serve to not only attain particular interests, but also reproduce and maintain the dominant logics and approaches of the most powerful (Fidler, 2004; Brand, 2005; Risse, 2007). A realistic assessment in the present context of global health partnerships probably lies somewhere between a critical and idealistic perspective, where the various actors neither serve as totally benevolent agents guided by altruism or selfinterested strategists attempting to maintain the status quo. Certainly, each sector has served as positive agents of change for ND, especially in collaboration, and has functioned as 'political entrepreneurs' (Keohane, 2001), with both the capacity and the incentives to invest in PDPs. This, of course, has not transpired without power and the pursuit of self-interested aims, and there has very likely been a focus on efficiency and effectiveness over equitable representation and deliberation.

Beyond the locus of power, it has been suggested that networked governance may employ different sources of power. In addition to traditional instruments of power, including resource and expertise transfer, perhaps more subtle, indirect forms also operate on and through these governance structures (Miller and Rose, 1992; Bang et al., 2000). Studies of these indirect forms of power have not been prominent, although various aspects have been addressed, such as information, knowledge, trust, and discursive processes. For example, information can serve as a tool to constrain and replace traditional means of exercising power. In this way, less powerful actors in a partnership may be able to mobilize external pressure and position against particular partners to shape their actions through the issuance of publicly available reports and use of the global media. While these alternative power mechanisms may be increasingly used in global partnerships, they are not likely to assume a key role in PDPs, as this particular partnership model to date relies heavily on traditional instruments, such as resource transfer and drug R\&D expertise. Moreover, the lack of Southern actor involvement probably hinders the introduction of alternative forms of power. For example, without meaningful involvement, Southern actors lack the ability to exert pressure (often via discursive processes) on Northern governments and private actors to intensify their efforts in improving the ND situation in their countries (Kohlmorgen, 2006).

Finally, the dynamics of PDP governance also reflect the broader political, economics, and ideological environment within which they operate. Such 
context favours certain strategies over others and, therefore, influences actors' and the partnership's ability to realize their objectives (Hays, 2002). Accordingly, respective actor and partnership strategies are modified, as are sometimes their underlying logics and interests, as it becomes apparent what is and is not feasible within a given context. This is a dynamic process, however, where actors also influence the broader context over time through assigning it meaning and via their actions. For example, the need to address NDs created a context where public-private collaboration was supported in the broader global health community and beyond, with significant discourse about its win-win offerings for all actors and a new paradigm for drug development activities (Trouiller et al., 2002). The fact that this approach was so positively positioned and reinforced by an influx of new PDPs presumably furthered the privatization of this governance arrangement and, in terms of other public-private partnerships, legitimized market logics and approaches as an organizing principle in global health governance and development. Perhaps this helps explain why public investment and direct government involvement in PDP activities has been minimal.

To conclude, while the PDP governance model offers significant benefits, there are also potential pitfalls associated with its structure, organization, and operationalization that should be taken into account and further examined. While 'public-private partnership' carries a positive, collaborative connotation, these are complex structures that do not operate sans power, politics, and divergent agendas. In relation, the term does not necessary accurately reflect who is represented and to what extent, as in the case of Southern actors. These partnerships have brought some tangible benefits, with new ND drugs on the market (e.g., MMV-Novartis Paediatric Coartem) or near registration; however, a focus on their technical effectiveness depoliticizes what is essentially a highly political process. To be sure, public-private partnerships highlight the complexities of global governance, such as balancing inclusiveness with efficiency, deliberation with transparency, and representation and direct participation. In practice, this model would perhaps work more effectively with greater theoretical and empiricalgrounding applied to its governance. While this editorial introduces some initial conceptions on PDP governance, the lens of inquiry should more systematically and robustly examine its actors, governance processes, and context in dynamic interaction. To achieve what Giddens (1990) deemed 'utopian realism', more extensive multi-disciplinary analysis is required to accurately assess the dynamics underlying PDPs, and how such a model can be improved to lend greater legitimacy, meaningful representation, and sustainability to global health governance, and, ultimately, to further progress towards eliminating NDs.

\section{References}

Bang, H.P. (2004), 'Culture governance: governing self-reflexive modernity', Public Administration, 82(1): 157-190. 
Bang, H.P., Hansen, A.D., and Hoff, J. (eds.) (2000), Democracy From Below: Case Studies from a Danish Municipality, Copenhagen: DJOF Forlag.

Barnett, M.N. and Duvall, R. (2005), Power in Global Governance, Cambridge, UK: Cambridge University Press.

Bartsch, S. and Kohlmorgen, L. (2007), The Role of Southern Actors in Global Governance: The Fights Against HIV/AIDS, Hamburg: Deutschen Uebersee-Instituts.

Benner, T., Reinicke, W.H., and Witte, J.M. (2005), 'Multisectoral networks in global governance: Towards a pluralistic system of accountability', in D. Held and M. KoenigArchibugi (eds.), Global Governance and Public Accountability, Malden: Blackwell.

Brand, U. (2005), 'Order and regulation: global governance as a hegemonic discourse of international politics', Review of International Political Economy, 12(1): 155-176.

Brogan, D. and Mossialos, E. (2006), 'Applying the concepts of financial options to stimulate vaccine development', Nature Reviews: Drug Discovery, 5: 641-647.

Buckup, S. (2008), 'Global public-private partnerships against neglected diseases: building governance structures for effective outcomes', Health Economics, Policy and Law, 3: 31-50.

Bull, B., Boas, M., and McNeill, D. (2004), 'Private sector influence in the multilateral system: a changing structure of world governance?', Global Governance, 10: 481-498.

Buse, K. (2004), 'Governing public-private infection disease partnerships', Brown Journal of World Affairs, 10(2): 225-242.

Buse, K. and Harmer, A. (2004), 'Power to the partners? The politics of public-private health partnerships', Development, 47(2): 49-56.

Buse, K. and Harmer, A. (2007), 'Seven habits of highly effective global public-private health partnerships: practice and potential', Social Science and Medicine, 64(2): 159-171.

Castells, M. (2000), The Rise of the Network Society: the Information Age, Economy, Society and Culture, 2nd edn, Oxford: Blackwell.

Deacon, B., Ollila, E., Koivusalo, M., and Stubbs, P. (2003), Global Social Governance: Themes and Prospects, Helsinki: Ministry for Foreign Affairs.

Drugs for Neglected Diseases Initiative (DNDi) (2006), 'Addressing the lack of research and development for neglected diseases', Available at: http://www.researchappeal.org/ dndi_pdf/RD_Briefing_for_EU_Feb06_final.pdf. (Accessed on 3 October 2008)

Dryzek, J.S. and Niemeyer, S.J. (2006), 'Reconciling pluralism and consensus as political ideals', American Journal of Political Science, 50(3): 634-649.

Fehr, A., Thurmann, P., and Razum, O. (2006), 'Drug development for neglected diseases: a public health challenge', Tropical Medicine and International Health, 11(9): 1335-1338.

Fidler, D. (2004), 'Germs, norms and power: Global health's political revolution', Law, Social Justice and Global Development, 1: 1-12.

Foucault, M. (2000), 'Governmentality', in J.D. Faubion (ed.), M. Foucault, Power, the Essential Works, Vol. 3, London: Allen Lane/Penguin Press.

Fraser, N. (2003), 'From discipline to flexibilization? Rereading Foucault in the shadow of globalization', Constellations, 10(2): 161-171.

Friedland, R. and Alford, R. (1991), 'Bringing Society Back In: Symbols, Practices, and Institutional Contradictions', in W. Powell and P. DiMaggio (eds.), The New Institutionalism in Organizational Analysis, Chicago: University of Chicago Press. 
Giddens, A. (1990), The Consequences of Modernity, Cambridge, UK: Polity Press.

Halabi, Y. (2004), 'The expansion of global governance into the Third World: Altruism, realism, and constructivism', International Studies Review, 6(1): 21-48.

Hay, C. (2002), Political Analysis: A Critical Introduction, Houndmills, UK: Palgrave Macmillan.

Keohane, R.O. (2001), 'Governance in a partially globalized world', American Political Science Review, 95(1): 1-13.

Kohlmorgen, L. (2006), The Role of Southern Actors in Global Health Governance: Access to Medicines and the Fight Against HIV/AIDS, Hamburg: German Overseas Institute.

Kooiman, J. (2003), Governing as Governance, London: Sage.

Marsh, D. and Smith, M. (2000), 'Understanding policy networks: towards a dialectical approach', Political Studies, 48: 4-21.

Martens, J. (2003), The Future of Multilateralism after Monterrey and Johannesburg: Dialogue on Globalization, Occasional Papers, No. 10, Berlin: Friedrich Ebert Stiftung.

Martens, J. (2007), Multistakeholder Partnerships: Future Models of Multilateralism? Berlin: Friedrich Ebert Stiftung.

Miller, P. and Rose, N. (1992), 'Political power beyond the state: problematics of government', British Journal of Sociology, 43(2): 173-205.

Moran, M., Ropars, A.L., Guzman, J., Diaz, J. and Garrison, C. (2005), The New Landscape for Neglected Disease Drug Development, London: The London School of Economics and Political Science and The Wellcome Trust.

Mrazek, M. and Mossialos, E. (2003), 'Stimulating pharmaceutical research and development for neglected diseases', Health Policy, 64(1): 75-88.

Reich, M. (2000), 'Public-private partnership for public health', Nature Medicine, 6(6): 617620.

Reinicke, W.H. and Deng, F. (2000), Critical Choices: The United Nations, Networks, and the Future of Global Governance, Ottawa: International Development Research Centre.

Risse, T. (2007), 'Social constructivism meets globalization', in D. Held and A. McGrew (eds.), Globalization Theory: Approaches and Controversies, Cambridge, UK: Polity Press.

Rose, N. (1999), Powers of Freedom: Reframing Political Thought, Cambridge, UK: Cambridge University Press.

Scharpf, F. (1997), Games Real Actors Play: Actor-Centered Institutionalism in Policy Research, Boulder: Westview.

Sending, O.J. and Neumann, I.B. (2006), 'Governance to governmentality: analyzing NGOs, States, and power', International Studies Quarterly, 50: 651-672.

Sorenson, E. and Torfing, J. (2003), 'Network politics, political capital, and democracy', International Journal of Public Administration, 26(6): 609-634.

Trouiller, P., Olliaro, P., Torreele, E., Orbinski, J., Laing, R., and Ford, N. (2002), 'Drug development for neglected diseases: a deficient market and a public health policy failure', Lancet, 359: 2188-2194.

Tucker, T.J. and Makgoba, M.W. (2008), 'Public-private partnerships and scientific imperialism', Science, 320(5879): 1016-1017. 
Widdus, R. (2003), 'Public-private partnerships for health require thoughtful evaluation', Bulletin of the World Health Organization, 81(4): 235.

Witte, J.M., Reinicke, W., and Benner, T. (2000), 'Beyond global public policy networks', Internationale Politik und Gesellschaft, 2: 176-188.

WHO (2007), 'Report on the Global Partners' Meeting on Neglected Tropical Diseases', Geneva: World Health Organization.

Yamey, G. (2002), 'The world's most neglected diseases', British Medical Journal, 325: 176-177. 